\title{
然
}

Luis Ramón Yanguas Morte*

Ángela Andrea Caviedes Conde**

\section{UN ESTUDIO SOBRE LAS VARIABLES ECONÓMICAS QUE INFLUYEN EN LA AYUDA OFICIAL AL DESARROLLO: INTRODUCCIÓN}

En este artículo se describen la evolución y características de la Ayuda Oficial al Desarrollo como antecedente de la presentación de un modelo econométrico descriptivo de determinadas variables sobre dicha ayuda. Este modelo, por su longitud, será presentado en un artículo complementario. Destacamos entre las variables el nivel de endeudamiento externo, la apertura comercial, el PIB per cápita y el acceso a capitales privados.

Palabras clave: Ayuda Oficial al Desarrollo, objetivos del desarrollo, objetivos del milenio. Clasificación JEL: F10, F63, O10.

\section{Introducción}

En una primera investigación ${ }^{1}$, que se publicó en el Boletín de Información Comercial Española n. 3093 , destacábamos el impacto de una variable como es la inversión privada en el desarrollo de los países en desarrollo. Se han proseguido nuestras investigaciones para completar la anterior con la presentación de un mayor número de variables económicas con incidencia en el desarrollo. Ellas se complementan con un estudio econométrico que será presentado en un trabajo complementario.

*Director de Finanzas. BCD TRAVEL, Atlanta, GA, Estados Unidos. Doctor por la Universidad de Alcalá. CPA, CMA

** Profesora de Marketing y Negocios Internacionales. Universidad Internacional de La Rioja. Doctora por la Universidad de Alcalá.

Versión de diciembre de 2017

1 Está basado en la tesis doctoral La financiacion internacional a los países en desarrollo en el siglo xxı, realizada por el Dr. Luis Yanguas, y dirigida por los doctores Miguel Ángel Díaz Mier y Ángela Andrea Caviedes Conde.

\section{La Ayuda Oficial al Desarrollo}

La Ayuda Oficial al Desarrollo (AOD) está recogida dentro de la rúbrica de balanza de pagos por cuenta corriente, en el capítulo de transferencias como subvenciones de un país a otro, unilaterales o multilaterales. Es una transferencia de origen público, entregada directamente o a través de instituciones multilaterales, en favor de los países en desarrollo, que tiene como objetivo principal la promoción del desarrollo económico y el bienestar de los países receptores, sin incluir la ayuda militar, y se otorga en términos financieros con una concesionalidad mínima del 25 por 100, o del 50 por 100 para los países muy endeudados.

Dentro de la AOD entregada a través de instituciones multilaterales podemos diferenciar: 
1. Las de las instituciones financieras internacionales (IFI), compuesta por los recursos voluntarios aportados por sus países miembros, no de las cuotas obligatorias, destinados a ejecutar proyectos de desarrollo en los países en desarrollo, prestar ayuda directa a sus balanzas de pagos (préstamos de ajuste estructural) y apoyar determinados programas presupuestarios de los receptores.

2. Las de las organizaciones internacionales no financieras, como agencias especializadas, programas y fondos de Naciones Unidas para promover la cooperación internacional, en los ámbitos técnico, científico, cultural, laboral, alimentario y sanitario, entre otros.

3. Los fondos multilaterales, que proporcionan financiación concesional (créditos y donaciones) a proyectos exclusivamente destinados a la promoción del desarrollo de los países en desarrollo.

Además de la AOD multilateral ha de considerarse la bilateral, que es la establecida directamente entre el país donante y el receptor, destacando en ella:

1. La AOD bilateral reembolsable, que comprende los préstamos concesionales que los Gobiernos de los países donantes otorgan a Gobiernos o instituciones públicas de los países beneficiarios para proyectos en sectores productivos o en el sector social y que bien pueden estar condicionados a la adquisición de bienes y servicios del donante (ayuda ligada) o acompañados por otros créditos oficiales a la exportación en condiciones de mercado (crédito mixto).

2. La AOD bilateral no reembolsable, que incluye las transferencias, en efectivo o en bienes y servicios, respecto a las cuales el beneficiario no contrae ninguna deuda legal.

Esta cooperación se compone de la ayuda humanitaria y/o alimentaria, la de emergencia, los proyectos de desarrollo económico y social, los programas de apoyo a la balanza de pagos, a las importaciones y al presupuesto del país receptor, la cooperación científica y técnica, las subvenciones a las ONG de desarrollo y los programas de reducción de deuda entre otros.

Por otro lado, entre los principales actores de la cooperación bilateral se encuentran:

1. La Administración central, principalmente por parte de los Ministerios de Asuntos Exteriores, de Economía y de Hacienda, ayudados generalmente por una agencia de cooperación al desarrollo especializada.

2. Las Administraciones territoriales distintas al Estado central que llevarán a cabo la cooperación oficial descentralizada.

3. Las ONG de desarrollo que canalizan en todos los países del Comité de Ayuda al Desarrollo un porcentaje creciente de la AOD bilateral no reembolsable, sobre todo en partidas destinadas al sector social y a la asistencia humanitaria y de emergencia.

4. Finalmente, cabe destacar cómo las empresas, sindicatos y universidades se están convirtiendo poco a poco en agentes con un protagonismo creciente.

Debe señalarse también que los instrumentos empleados para la AOD varían en función del contexto, y su elección y uso reflejan tanto el grado de compromiso del país donante con la lucha contra la pobreza como su elección $\triangleright$ 
de intervenir en determinados sectores del país receptor.

En general, se pueden destacar: i) la ayuda proyecto, empleada como complemento a las políticas de los Gobiernos receptores y a las habilidades locales técnicas de gestión y organización, que está bastante condicionada por la situación macro del país o región receptora y suscita bastantes críticas 2 ; ii) la ayuda programa, que se compone, en general, de las contribuciones puestas a disposición del país receptor con fines generales de desarrollo no vinculadas a proyectos específicos, siendo sus receptores los Gobiernos de los países en desarrollo. Estas pueden categorizarse en la ayuda alimentaria, el apoyo a la balanza de pagos (programas de reducción de deuda), apoyo a las importaciones a través de la entrega de insumos o divisas atadas y apoyo a la balanza de pagos con divisas liquidas no atadas y apoyo al presupuesto. A excepción de la ayuda alimentaria, el resto son tipologías muy recientes y con bastantes ventajas ${ }^{3}$; finalmente, iii) la cooperación técnica, financiada por un donante externo cuyo objetivo básico es elevar el nivel de conocimiento, la cualificación, el aprendizaje práctico o la capacidad productiva de los

\footnotetext{
2 Si bien este instrumento focaliza el impacto sobre problemas o poblaciones objetivo específicos y presenta una menor fungibilidad que la ayuda programa al contar con una finalidad específica para los recursos entregados, puede generar duplicidades ante la proliferación de proyectos de las distintas organizaciones donantes, tiene un mayor sesgo hacia los intereses del donante especialmente en la ayuda vinculada, requiere de una definición precisa entre las fases a realizar por donante y receptor que permita el desarrollo de este último y el fortalecimiento de sus instituciones y puede en ocasiones generar mayor distorsión en las cuentas públicas del país receptor al expandir su gasto público si se aplican condiciones de financiación a nuevas inversiones.

3 En general, confieren un mayor protagonismo al país receptor y permiten un mayor desarrollo de sus capacidades (siempre que no existan niveles inadecuados de condicionalidad de la misma), su ejecución es más rápida y sencilla al no estar sometida al ciclo del proyecto, permite mayor flexibilidad en su uso, pudiendo utilizarse para gastos de mantenimiento de inversiones anteriores; resulta adecuada en condiciones de brecha fiscal al recibir divisas y permitir, por regla general, incrementos de importaciones y reducciones de déficit público (si el fondo contravalor de la venta de divisas se integra en el presupuesto nacional) y estrecha los lazos de las políticas entre donante y receptor al acordar el uso en la ejecución de la misma.
}

países receptores, no exenta de ventajas y riesgos ${ }^{4}$.

\section{Análisis comparativo}

La evolución de la AOD durante los años sesenta estuvo marcada por los compromisos adoptados para la promoción del desarrollo y una experiencia incipiente en las relaciones donante-receptor. A partir de 1970, con el impulso derivado del objetivo del 1 por 100 del PIB aprobado en la Asamblea General de Naciones Unidas de 1970, que estableció la AOD como el canal oficial de ayuda a los países en desarrollo, las tasas de crecimiento de tal ayuda durante los años setenta y ochenta fueron superiores a las de la producción mundial y prácticamente similares a las del comercio internacional, con alguna excepción ${ }^{5}$.

A partir de los años noventa, la evolución de las tasas de crecimiento de la AOD entraron en una fase de recesión con crecimientos promedio inferiores al comercio internacional, fase conocida como la de «fatiga del donante», que duraría hasta finales del siglo xx y cuyas raíces habría que buscarlas no solo en los importantes cambios del entorno internacional, sino también en las dudas que suscitaba su eficacia real como instrumento al servicio del $\triangleright$

\footnotetext{
4 Resulta idónea para incrementar el capital humano del país receptor y permite la transformación e innovación en este, especialmente cuando se emplean las tecnologías adecuadas y se fomenta la participación de homólogos nacionales en el país receptor, si bien requiere un control sobre la contratación de expatriados y los niveles salariales ofrecidos por sus posibles impactos en el mercado laboral local, la canibalización de expertos locales, así como posibles fugas de cerebros, y debe estar perfectamente alineada con las necesidades del país receptor.

5 Durante 1981 y 1983 se produjo un punto de inflexión motivado por el impacto de la guerra de Irán e Irak, la segunda crisis del petróleo, las crisis de deuda latinoamericanas y el comienzo de la Guerra Fría, que llevaron a una reducción del total de entradas de AOD que se recuperarían posteriormente a lo largo de la década y de manera aún más significativa en los dos últimos años, incluso a pesar de los comienzos de la crisis económica mundial en 1989 y del derrumbe de las economías de la antigua Unión Soviética.
} 
desarrollo, ya que, pese a las señaladas cuatro décadas de experiencias y programas, las causas que motivaron el nacimiento de sistemas como el de la AOD seguían existiendo ${ }^{6}$.

Durante el siglo xxI se observa de nuevo un cambio de tendencia y las tasas de crecimiento se vuelven a igualar con las del comercio internacional. Es en este periodo cuando la AOD ha registrado los mayores crecimientos de la historia en términos absolutos, destacando especialmente el buen comportamiento mostrado durante los últimos cinco años a pesar del impacto internacional de las tensiones inflacionistas derivadas del incremento del precio del petróleo, la ralentización del mercado de vivienda y construcción, la crisis financiera y de crédito y la subsiguiente recesión y crisis de deuda de las economías desarrolladas.

Atendiendo a las tipologías de la AOD, las tendencias de evolución de los años noventa se han mantenido a lo largo del siglo xxı. Por un lado, tanto la tendencia creciente de los subsidios de condonación de deuda impulsados por las diferentes iniciativas de condonación de deuda a los países pobres muy endeudados, con especial impacto en 2005 y 2006 (Irak y Nigeria especialmente), como la tendencia creciente de la asistencia humanitaria desde los primeros años de la década de los noventa hasta la actualidad y, por otro lado, la tendencia creciente de las entradas netas de la AOD multilateral, que a lo largo del siglo xxI, si bien no han continuado creciendo, sí se han mantenido especialmente durante los años de mayor impacto de la crisis.

La tendencia decreciente de las indicadas ayuda programa, ayuda proyecto y asistencia técnica bilateral se ha acelerado con la entrada

6 Cambios marcados por el hundimiento de las economías del Este y la recesión mundial de 1991 y 1993 con episodios de estanflación, caída del crédito y de estancamiento de la producción en determinados países. del nuevo siglo, volviéndose a recuperar levemente en los últimos años del periodo de análisis. Esta tendencia supone una reducción de las entradas de donaciones reales y previsibles hacia los países donantes y tiene un impacto muy importante en el desarrollo de sus economías, debido a: i) los subsidios de condonación de deuda (en que se da por incobrable la deuda de un país y se mejoran las condiciones de endeudamiento y de servicio de la deuda) no suponen un desembolso de fondos, ii) la asistencia humanitaria responde a condiciones excepcionales y finalidades específicas que no pueden considerarse como previsibles ni tenerse en cuenta en las estrategias nacionales de desarrollo de los países y iii) la AOD multilateral contiene un mayor componente de crédito blando en condiciones especiales y la necesidad de someterse al cumplimiento de los programas de ajuste, que no deja de suponer un empeoramiento de la posición deudora del país receptor y del ratio de donaciones respecto a créditos.

A su vez, se destaca el importante incremento de los fondos internacionales con propósitos especiales como los de inversión en mejoras del medioambiente o la lucha contra determinadas enfermedades, todos ellos enfocados a tratar la problemática de los bienes públicos globales con fondos distribuidos desde donantes privados u oficiales. Aún no está del todo claro si este tipo de fondos perturban las estrategias nacionales de desarrollo al requerir, en última instancia, de determinados recursos nacionales para su ejecución que serían detraídos de otros programas.

En relación con las entradas netas de Ayuda Oficial al Desarrollo como instrumento de ayuda de último recurso a los países más pobres y en una situación más crítica, en determinados países se viene produciendo una falta de $D$ 
sostenibilidad de la misma, denunciada desde muchos foros ${ }^{7}$, que produce un efecto adverso sobre las economías receptoras, que, tras recibir determinadas cuantías en un año concreto, ven cómo la misma se reduce drásticamente al siguiente, impidiendo dar continuidad a planes, políticas y programas de desarrollo a nivel nacional en aras del cumplimiento de los objetivos de desarrollo del milenio, y poniendo de manifiesto la necesidad de impulsar los principios de la Declaración de París y, en concreto, la responsabilidad mutua donante-receptor.

Cabe resaltar que la evolución de la AOD mundial en las últimas décadas ha estado determinada por una serie de seis factores que explican tanto su gran crecimiento como su menor volatilidad en respuesta a la evolución económica mundial. Dichos factores son los siguientes:

1. Destaca la evolución de los compromisos políticos internacionales asumidos por los países donantes con respecto al desarrollo de los países en desarrollo, especialmente a lo largo del siglo $\mathrm{xxl}^{8}$. Dentro de dichos compromisos destacan: a) el incremento del volumen de AOD en relación con el ingreso nacional bruto de los países donantes hasta alcanzar la cifra del 0,7 por $100^{9}$; y b) que se haya

\footnotetext{
7 Grupo de Tareas sobre el desfase en el logro de los objetivos de desarrollo del milenio, para casos como Bangladés, Bolivia, Camboya y Uganda en 2010.

8 Fue a partir de la Declaración del Milenio de las Naciones Unidas cuando se adoptaron compromisos para incrementar el volumen y la eficacia de la Ayuda Oficial al Desarrollo para reducir la pobreza y para alcanzar el resto de objetivos de desarrollo del milenio. Estos objetivos han caracterizado gran parte de las políticas internacionales de Ayuda Oficial al Desarrollo desde comienzos del milenio y los diferentes foros de seguimiento de los mismos, a destacar la Conferencia de Monterrey 2002, la Declaración de Principios de la Conferencia de París y las conferencias internacionales de seguimiento de los avances (Doha, Accra, Busan), así como los esfuerzos y medidas de emergencia adoptados para contribuir a la respuesta a la crisis mundial: G20, FMI, Banco Mundial, etcétera.

9 En 1969, a partir del Informe Pearson surgió la recomendación de dedicar el 0,7 por 100 de la riqueza nacional de los países ricos al desarrollo de los más pobres. A partir de aquí ha sido retomado en determinadas cumbres y foros.
}

destinado al menos un 0,15 por 100 a los países menos adelantados y que debe contar con un subsidio o donación de al menos el 50 por 100 para el caso de los países menos adelantados, y el resto en forma de préstamos en condiciones favorables. El volumen de AOD no se ha cumplido, sino que viene reduciéndose desde el máximo histórico de 196, alcanzando, en 2013, el 0,4 por 100 (0,3 por 100 en países del Comité de Ayuda al Desarrollo de la OCDE), con cinco países que cumplen el objetivo o están por encima del mismo (Luxemburgo, Noruega, Suecia, Reino Unido y Emiratos Árabes Unidos, con 1,25 por 100 tras dar soporte excepcional a Egipto) y con cuatro grandes donantes que por su cuantía puede señalarse que están incumpliéndolo (EEUU, Francia, Alemania y Japón).

Por otra parte, el objetivo de la Ayuda Oficial al Desarrollo a los países menos adelantados puede considerarse cumplido a nivel total mundial, con valores cercanos al 20 por 100. Dichos países son los que concentran el mayor monto de la AOD recibiendo en torno a un tercio de la ayuda total de los donantes. En cualquier caso, es de destacar positivamente: a) el crecimiento sostenido del monto de Ayuda Oficial al Desarrollo per cápita en los países receptores especialmente a partir del año 2000 en que llega a duplicarse y b) que el nivel general de tasas de crecimiento de la Ayuda Oficial al Desarrollo ha sido más estable en relación con las de los capitales privados, mostrando una menor volatilidad.

2. Se destaca igualmente el creciente incremento de la componente de donaciones de la $A O D$ en detrimento de $D$ 
dichos préstamos. Esta tendencia se ha visto acelerada a lo largo del siglo XXI en respuesta a los episodios de crisis de deuda sufridos a lo largo de la década de los ochenta y las diferentes iniciativas de sostenibilidad de la deuda acometidas sobre los países pobres muy endeudados.

Esta evolución es crucial para los países más pobres, ya que evita que la ayuda agrave la carga de la deuda de los mismos. En la última década las donaciones han alcanzado valores superiores al 90 por 100 de las entradas netas de Ayuda Oficial al Desarrollo, considerando tanto la bilateral con mayor porcentaje de donaciones y la multilateral con mayor porcentaje de préstamos, si bien dicha evolución ha empeorado en los últimos tres años, en parte por las medidas de emergencia multilaterales de respuesta a la crisis.

3. Otro factor a señalar ha sido la evolución positiva en el grado de condicionalidad de la ayuda, es decir, en la reducción casi total de las restricciones impuestas a que los fondos de la AOD se destinen exclusivamente a adquirir bienes o servicios procedentes del país donante. A lo largo de la década de 1980 comenzaron a tomarse medidas para reducir el grado de condicionamiento desde valores cercanos al 50 por 100 del total de AOD. Fue a partir de 1990 cuando cambia la tendencia y podemos observar cómo la propensión de reducción progresiva de la misma se ha mantenido a lo largo del siglo xxI, si bien con fluctuaciones en el periodo 2007 a 2009, cuando a pesar de que países como Irlanda, Luxemburgo, Noruega o Reino Unido mostraron casi un 100 por 100 de no condicionamiento, otros países como República de Corea, Grecia o Portugal mantuvieron fuertes niveles de condicionamiento en el caso de los países europeos, en parte debido al impacto de las medidas fiscales en sus economías.

4. En cuarto lugar, se destaca que a lo largo de los años noventa se produjo una importante concentración en el grupo de países donantes miembros del Comité de Ayuda al Desarrollo de la OCDE que se ha mantenido a lo largo del siglo XXI, si bien durante los últimos años se ha invertido ligeramente la tendencia, con reducciones en el porcentaje de participación de los países del entorno del euro motivada principalmente por el impacto de las medidas fiscales adoptadas por los mismos, especialmente en los casos de Francia, España, Portugal, Italia y Grecia.

Así mismo, como se muestra, se ha producido una creciente participación de los países no miembros del Comité de Ayuda al Desarrollo como donantes de Ayuda Oficial al Desarrollo mundial y que tras unos años de máximos históricos a lo largo de los años setenta y ochenta (liderados principalmente por los países del entorno árabe como Arabia Saudí, Emiratos Árabes, Kuwait, etcétera), en la década de los noventa comenzaron a mostrar una paulatina tendencia creciente que se ha acelerado a lo largo del siglo xxı, reflejando lo que se ha dado en llamar el desarrollo de la cooperación Sur-Sur.

Esta evolución ha sido impulsada nuevamente por las aportaciones de los países árabes y también los países en transición europeos y Turquía, así como por $D$ 
otros países, como los BRIC, que han comenzado a establecer estrategias de AOD hacia países de ingreso medio y medio bajo dentro de sus áreas de influencia, llegando a alcanzar cifras cada vez más cercanas al 10 por 100 y sin tener en cuenta todos los tipos de cooperación no incluidos dentro de estas cifras, bien por motivos de finalidad como por falta de datos, como en el caso de China, India, Venezuela u otros.

5. En quinto lugar, se encuentra la relación con el grado de concentración de los países receptores, y la tendencia observada a lo largo de las últimas décadas del siglo pasado se ha visto frenada durante el siglo xxı. Incluso si descontamos el efecto de los planes de condonación de deuda a países pobres muy endeudados en Irak y Nigeria durante los años 2004 a 2006, se ha producido un estancamiento.

En cualquier caso, las cifras de concentración de receptores mostradas por las entradas netas de AOD son las más bajas de todos los instrumentos financieros internacionales analizados, a pesar de lo cual existe un sesgo importante hacia los tres principales receptores que en varios años han sido Irak, Afganistán y Etiopía por motivos diversos y que están bastante lejos de los volúmenes recibidos por el resto de países. Ello mantiene abierto el debate respecto a los criterios de asignación de la Ayuda Oficial al Desarrollo ${ }^{10}$.

6. En último lugar, hay que destacar que el incremento de las entradas netas de

10 Por un lado, sigue todavía muy vinculado a las estrategias nacionales de los países donantes debido al todavía elevado porcentaje de ayuda bilateral y que, por otro lado, supone en ocasiones dejar fuera del paraguas de ayuda a los países no incluidos en las listas de países menos adelantados o países pobres muy endeudados, como es el caso, por ejemplo, de los países de ingreso medio que en ocasiones tienen dificultades al no estar amparados bajo ningún instrumento concreto.

\begin{abstract}
AOD multilateral de los últimos años, motivadas por los esfuerzos políticos de las economías desarrollas por impulsar planes de contingencia tanto el FMI como el Banco Mundial, han supuesto un desgaste de fondos que pueden poner en peligro la continuidad a los mismos niveles en los próximos años.
\end{abstract}

\section{Análisis por países en el siglo xxI}

Una vez examinadas las características generales de la evolución de la AOD, se considerarán el nivel de renta de los países en desarrollo receptores de ayudas, examinando especialmente la tendencia de crecimiento de entradas netas de la AOD a los países de renta baja y medio alta, y de reducción a los países de renta medio baja que en los años ochenta sufrieron un punto de inflexión durante la indicada década de la fatiga del donante, en la que se produjo un estancamiento en términos porcentuales de entradas totales hacia los países de renta baja y medio baja, por las razones comentadas anteriormente respecto a las dudas de efectividad de la misma.

A lo largo del siglo xxI se produce un cambio de tendencia motivado por la Declaración del Milenio y los compromisos de ayuda a los países más pobres que se vio traducido en una creciente evolución del porcentaje de las entradas totales de Ayuda Oficial al Desarrollo hacia los países de menor nivel de renta y un mantenimiento de entradas hacia los países de renta media baja, a excepción del periodo 2005 y 2006, fuertemente influenciado por el impacto de la asistencia humanitaria y la condonación de deuda a Irak, Afganistán, Indonesia y Sudán, entre otros. Adicionalmente, se observa una tendencia decreciente en el porcentaje $D$ 
de entradas netas de AOD hacia países de renta medio alta y alta que se mantendrá hasta nuestros días. Desde el punto de vista de la evolución regional, el porcentaje de entradas netas de Ayuda Oficial al Desarrollo a nivel regional ha variado profundamente en los últimos cincuenta años.

La región del África Subsahariana ha mostrado una creciente evolución en el porcentaje de entradas netas mundiales de AOD, que ha sido especialmente destacable a lo largo de los años ochenta, reflejo de las diversas acciones llevadas a cabo (Plan de Lagos, Informe Berg, planes de ajuste Banco Mundial y FMI), así como el impacto de la crisis de los países de la periferia. Esta región concentra la gran mayoría de los países menos adelantados del mundo y casi el 100 por 100 de sus países integrantes son de renta baja. En las últimas décadas ha sufrido un sinfín de conflictos políticos y bélicos que han hecho que sea extremadamente sensible y dependiente de la AOD para su subsistencia y desarrollo.

Tras el cambio de tendencia hacia una fase de estancamiento y leve reducción del porcentaje total de entradas de AOD durante la década de la fatiga del donante, será a partir del siglo XXI cuando se producirá un giro en la política de asignación de Ayuda Oficial al Desarrollo hacia los países más pobres y de renta baja, mostrando los mayores crecimientos registrados, efecto de las diversas iniciativas como, por ejemplo, los diversos planes de condonación de deuda (especialmente importantes en el caso de Nigeria, Zambia, Etiopía y Ghana entre 2005 y 2006, y Congo en 2010), el Plan de Acción Kannaskis y el Plan África 2009-2012, entre otros, fruto de los acuerdos para reorientar la Ayuda Oficial al Desarrollo hacia los países más pobres y hacia la consecución de los objetivos de desarrollo del milenio en 2015, que han llevado a duplicar el volumen real de recursos recibidos por la región desde 2000 hasta la actualidad.

La región de Asia Meridional ha mostrado una evolución decreciente del porcentaje de entradas netas mundiales de la AOD desde las cifras máximas históricas de los años sesenta, y a pesar del crecimiento en volumen registrado desde los primeros datos hasta los años ochenta, con crecimientos importantes de ayuda especialmente multilateral en India, Bangladés y Sri Lanka. Durante la década de los noventa continuará dicha tendencia decreciente respecto del total de Ayuda Oficial al DesarroIlo mundial, produciéndose además reducciones en volumen causadas por la reducción de ayuda especialmente multilateral y bilateral de proyectos a India y Pakistán.

Será a partir del siglo xxI cuando se producirá un cambio de tendencia con un ligero crecimiento del porcentaje de entradas totales netas de Ayuda Oficial al Desarrollo motivado, en primer lugar, por el crecimiento de la ayuda bilateral a proyectos especialmente de EEUU a Afganistán tras la guerra en este país y, en menor medida, a Pakistán, así como el crecimiento de la ayuda multilateral hacia India, Pakistán, Afganistán y Bangladés y los planes de condonación de deuda aplicados a este último de 2002 a 2004 y a Pakistán de 2003 a 2008 especialmente. En la región de Oriente Medio y Norte de África se observa una evolución decreciente respecto a los máximos históricos de los años setenta que continuará durante los años ochenta y noventa, donde pasó de valores superiores al 20 por 100 de entradas mundiales a valores por debajo del 10 por 100 en 1995.

Esta evolución se produjo principalmente por el retroceso de las entradas de Ayuda Oficial al Desarrollo multilateral y bilateral de $\triangle$ 
proyectos a Israel, Egipto, Siria y Marruecos, y a pesar del crecimiento de la asistencia humanitaria en Egipto y Libia durante los años noventa y las iniciativas de condonación de deuda registradas en Egipto y, en menor medida, en Marruecos entre 1989 y 1992. A partir del siglo $\mathrm{xxI}$ observamos un cambio de tendencia con una recuperación del porcentaje de entradas netas mundiales de Ayuda Oficial al Desarrollo, motivado por los crecimientos de las entradas de ayuda bilateral para proyectos en buena parte financiada por la Liga Árabe y por países con intereses poscoloniales y, en menor medida, por el crecimiento de la asistencia humanitaria a partir del año 2000 hacia Egipto, Siria y Marruecos, y por el impacto de los planes de condonación de deuda (principalmente a Siria en 2005).

En la región de América Latina y Caribe observamos una tendencia decreciente desde los niveles máximos históricos del porcentaje de entradas netas mundiales de Ayuda Oficial al Desarrollo registrados a finales de los años sesenta y hasta los niveles mínimos registrados a finales de los años setenta. Durante los años ochenta cambia la tendencia y pasa a crecer el porcentaje de entradas netas mundiales de Ayuda Oficial al Desarrollo y continuará así hasta mitad del periodo, a pesar de las crisis de deuda registradas en varios países de la región, reflejando el impacto de la creciente ayuda multilateral recibida en países como Brasil, Colombia y Perú, así como los planes de condonación de deuda aplicados en esta década en países como México, Brasil, Argentina, Chile y Venezuela.

Durante los años noventa se produce un estancamiento en los primeros años para pasar posteriormente a crecer debido principalmente al incremento de la ayuda multilateral entre 1996 y 1997 en países como Brasil, Bolivia y
Argentina, los planes de condonación de deuda de Nicaragua, Bolivia, Brasil y Ecuador, entre otros, y el paulatino aunque todavía no muy significativo crecimiento de la asistencia humanitaria hacia la región.

Con la entrada del siglo xxı se produjo nuevamente una reducción del porcentaje de entradas netas mundiales de Ayuda Oficial al Desarrollo durante los primeros años y hasta 2005, año a partir del cual cambió la tendencia y comenzó de nuevo a crecer, consiguiendo mantenerse el nivel durante todo el periodo. Esta recuperación a partir de 2005 se ha debido principalmente al impulso de la ayuda multilateral a nivel regional, al crecimiento de la asistencia humanitaria, como en Chile en 2010, y principalmente por los planes de condonación de deuda de Argentina en 2005 y 2010, Honduras, Haití, México y Perú durante el periodo. Este crecimiento ha sido especialmente importante a pesar de la reorientación de la AOD mundial hacia los países menos adelantados, que impacta negativamente en la región, dado que la mayoría de países son de renta media.

En la región de Asia Oriental y Pacífico se observa una paulatina tendencia decreciente del porcentaje del total de entradas mundiales de Ayuda Oficial al Desarrollo, desde los niveles máximos de 1972, con una posterior fase de estancamiento en los años ochenta y noventa, y de posterior reducción durante el siglo xXI. Esta reducción se ha producido a pesar del leve crecimiento en volumen mostrado tanto en asistencia humanitaria como en ayuda multilateral durante el siglo xxI, especialmente a países como Indonesia, Vietnam, Filipinas y Corea, pero que no ha sido comparable a la del resto de regiones.

En la región de Europa y Asia Central se produjo un crecimiento importante del $\triangleright$ 
porcentaje de entradas netas de Ayuda Oficial al Desarrollo mundial durante la década de los noventa, motivado por el hundimiento de la antigua Unión Soviética y la creación de países en transición del este de Europa como son Polonia, Rumanía, Serbia, Federación Rusa, Ucrania y que, con mayor o menor medida, continuó hasta la incorporación de diez países a la Unión Europea en 2004 (República Checa, Chipre, Estonia, Hungría, Letonia, Lituania, Malta, Polonia, República de Eslovaquia y Eslovenia), cuatro de ellos miembros de la OCDE, lo que, junto al importante crecimiento económico de la región en esos años, supuso la reducción del volumen de AOD recibida, especialmente a nivel bilateral de proyectos y a pesar de los planes de condonación de deuda de la Federación Rusa y Serbia realizados durante el periodo.

\section{El gap de recursos financieros para los objetivos de desarrollo actuales y los nuevos desafíos}

Es importante, en este punto, reconocer que desde el origen de la Agenda Institucional del Desarrollo ha perdurado hasta nuestros días un grave problema de insuficiencia de recursos financieros con los que costear el cumplimiento de los compromisos internacionales adoptados, y cómo esa falta de fondos ha ido socavando la credibilidad de dichos compromisos $y$, por ende, de la voluntad de cumplimiento de los mismos.

Ya en los años noventa, la Comisión Europea solicitó al secretario general de Naciones Unidas que estableciera - con urgencia- un inventario completo y detallado del conjunto de los programas prioritarios objeto de un acuerdo internacional, con una estimación de su costo y de los compromisos de financiación, con el objetivo de establecer una regulación general de las metas que abarcase todo el sistema, si bien, a pesar de las elevadas cuantías afloradas, continuó la resistencia a los compromisos financieros vinculantes.

Más adelante, tras la Cumbre del Milenio y la fijación de los Objetivos de Desarrollo del Milenio, encontramos en 2004 otro análisis similar, en el que, partiendo de las evaluaciones preliminares de las necesidades relacionadas con los objetivos de desarrollo del milenio del Proyecto del Milenio de las Naciones Unidas en Bangladés, Camboya, Ghana, Tanzania y Uganda, se analizaron las necesidades de recursos financieros desde 2006 hasta 2015 para asegurar dicho cumplimiento en el contexto de países de ingreso bajo. Con base en sus conclusiones, la mayoría de los países de bajos ingresos tendría un déficit de financiación de los Objetivos de Desarrollo del Milenio de entre un 10 y un 20 por 100 del PIB, que sería necesario subsanar mediante un incremento de la Ayuda Oficial al Desarrollo.

Por otro lado, existen importantes gaps previstos en el cumplimiento de los Objetivos de Desarrollo del Milenio 2015 y nuevos desafíos de la Agenda del Desarrollo Post 2015, tales como el crecimiento de la población mundial, los objetivos de erradicación total (no dejar a nadie atrás) o el desafío medioambiental, que hacen de este, sin lugar a dudas, el momento histórico en que la humanidad se enfrenta a las mayores necesidades de recursos financieros para poder cumplir con sus compromisos internacionales acordados.

Si bien en estos momentos resulta vital disponer de las estimaciones de los recursos financieros necesarios para poder gestionar el gap de los recursos financieros disponibles, también resulta igual de importante entender $D$ 
que no existe una cifra global correcta, ya que la tarea de cuantificar las necesidades es compleja y necesariamente imprecisa por depender de diversos factores, entre ellos el entorno macroeconómico y de políticas (tanto el sectorial como el del conjunto de la economía), las reglas, normas y estándares internacionales, la eficacia con que se utilicen los recursos financieros y las posibles sinergias y el carácter intersectorial del desarrollo sostenible, entre otras cosas.

En este sentido, cabe destacar el esfuerzo por recabar la mejor información disponible realizado por Naciones Unidas, cuyas cifras globales ascienden a un total conjunto, aunque no necesariamente dicho total sea sumable, en torno a los 20.000 millones de dólares anuales, en base a las estimaciones centradas en tres frentes: el desarrollo, la infraestructura y el medioambiente y los bienes públicos.

1. En primer lugar, dentro del desarrollo se recogen las necesidades básicas relacionadas con la erradicación de la pobreza y el hambre, la mejora de la salud y la educación, el acceso a energía asequible y la promoción de la igualdad de género, con unas necesidades de recursos financieros anuales globales de alrededor de 195.000 millones de dólares que recogen, entre otros, el establecimiento de una red mundial de seguridad para erradicar la pobreza extrema en todos los países con cerca de 66.000 millones de dólares anuales y la cobertura de las necesidades de inversión para el hambre, la salud y la educación, valoradas en torno a 129.000 millones de dólares anuales ${ }^{11}$.

11 Las cifras recogen 50.000 millones de dólares anuales para erradicar el hambre antes de 2025, 37.000 millones de dólares anuales para lograr la atención médica universal y 42.000 millones de dólares
2. En segundo lugar, dentro de la infraestructura se recogen las necesidades de financiación para invertir en el desarrollo sostenible nacional, la creación de empleo y de infraestructura (desarrollo rural, adaptación al cambio climático y energía), con unas necesidades de recursos financieros anuales globales de entre 8,5 y 10,5 millardos de dólares anuales, que recogen, entre otros: la inversión en infraestructura en los sectores industrial, del agua, la agricultura, las telecomunicaciones, la energía, el transporte, la construcción y la silvicultura, que se ubican entre los 5 y los 7 millardos de dólares a nivel mundial ${ }^{12}$, y el restablecimiento de las necesidades de crédito a las pequeñas y medianas empresas, como principales fuentes de empleo y que se estima en 2,5 millardos de dólares anuales en los países en desarrollo y 3,5 millardos de dólares anuales a nivel mundial, según los autores Stein, Goland, y Schiff (2010).

3. En tercer lugar, las necesidades de financiación para el suministro de bienes públicos mundiales, como la protección del medioambiente mundial y la lucha contra el cambio climático y sus efectos, con unas necesidades de recursos financieros globales de entre 3 y 3,5 millardos de dólares anuales, que recogen, entre otros, las necesidades de protección de los océanos, los bosques y la $D$

anuales para alcanzar la enseñanza primaria universal e incrementar el acceso al primer ciclo de la enseñanza secundaria, según datos de Romilly Greenhill y Ahmed Ali, «Paying for progress: how will emerging post-2015 goals be financed in the new aid landscape?», Documento de Trabajo n. 366, Overseas Development Institute, Londres, 2013.

12 Las cifras en base a las estimaciones recogidas en el informe The Green. Investment Report: the ways and means to unlock private finance for green growth, del Green Growth Action Alliance, Foro Económico Mundial de Ginebra, 2013. 
biodiversidad, que se estiman en torno a 460.000 millones de dólares, y las necesidades para la mitigación y adaptación al cambio climático, que se estiman en torno a 2,6-3 millardos de dólares anuales. Teniendo en cuenta el volumen de recursos financieros disponibles del análisis de los instrumentos tradicionales de financiación al desarrollo y la coyuntura económica mundial antes comentados, resulta evidente que los recursos financieros tradicionales no son suficientes para asegurar el cumplimiento de los compromisos internacionales en los próximos años, mientras que los países no están en disposición de incrementar sus aportaciones con cargo a sus presupuestos nacionales y el mundo, por tanto, se enfrenta al mayor gap de recursos financieros de la historia.

\section{Bibliografía}

[1] AABY, N. E. y SLATER, S. (1989). "Management Influences on Export Performance: A Review of the Empirical Literature 1978-1988». International Marketing Review, vol. 6, n. $\circ 4$.

[2] ALONSO, J. A. y DONOSO, V. (1994). «Competitividad de Empresa Exportadora Española». Instituto Español de Comercio Exterior. Madrid.

[3] ARTARAZ, M. (2002). «Teoría de las tres dimensiones del desarrollo sostenible». Revista Ecosistemas, vol. 11, n.․ 2 .

[4] AZARIADIS, C. (2006). The Theory of poverty traps. What have we learned. Priceton University Press.

[5] BANCO IBERAMERICANO DE DESARROLLO (2007). Triennial Central Bank Survey of Foreign Exchange and Derivatives Market Activity. Disponible en: http://www.iadb.org (Recuperado: 2014, 5 de enero).
[6] BANCO MUNDIAL (2014). Reseña sobre Migración y Desarrollo 2014. Comunicado de prensa.

[7] BEVAN, A. A. y ESTRIN, S. (2000). Patterns of foreign direct investment and trade in Central and Eastern Europe, mimeo.

[8] BORJAS, G. J. (1989). Economic theory and international migration.

[9] BOWLES, S.; DURLANF, S.N. y HOFF, K. (2006). Poverty traps. Princeton University press.

[10] BUCKLEY, P.J. y CASSON, M. (1976). The future of the multinational Enterprise. Ed. MacMillan.

[11] CALDUCH CERVERA, R. (1991). «La sociedad internacional». Relaciones Internacionales. Ediciones Ciencias Sociales.

[12] CASTELAZO, J. R. (2007). Administración Pública, una visión de Estado. INAP. México.

[13] CAVUSGIL, T. y SHAOMING, Z. (1994). «Marketing Strategy-Performance Relationship: An Investigation of the Empirical Link in Export Market Ventures». Journal of Marketing, n. .58 , pp. 1-21.

[14] COHEN, G. A. (2001). If you are Egalitarian, How come you are so rich? New Ed.

[15] DÍAZ MIER, M. A. y CAVIEDES, A. (1996). La OMC y sus Conferencias Ministeriales. Trabajo de Investigación Universidad de Alcalá de Henares.

[16] DORNBUSCH et al. (1983). «The Black Market for Dollars in Brazil». National Bureau of Economic Research, n. 0590.

[17] DUNNING, J. (1973). «The determinants of International production». Ed. Oxford Economic Papers. Oxford University Press, vol. 25, n. $\stackrel{\circ}{ }$ 3, pp. 289-336.

[18] DURAN HERRERA, J. J. (1994). «Internacionalización de la empresa española en la crisis. Exportaciones e inversión directa». Revista Economistas.

[19] EATON WILLIAMSON, O. (2000). «The new institutional economics: Taking stock, Looking Ahead». Journal of Economic Literature, vol. 38, pp. 595-613.

[20] FAINI, R. y VENTURINI, A. (1994). «Migration and growth: the experience of Southern Europe». Discussion Paper, n.-964. Londres: Centre for Economic Policy Research. 
[21] FONDO MONETARIO INTERNACIONAL. (2014). Global Financial Stability Report: Moving from liquidity to growth-driven markets.

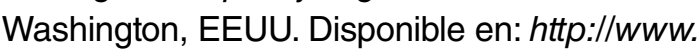
fmi.org. (Recuperado: 2014, 5 de enero).

[22] GARCÍA ARIAS, J. (2008). «Finanzas Internacionales y Desarrollo, ¿Oportunidad o Amenaza?». CEPAL, n.ㅇ 96, p. 161.

[23] GASTANAGA, V. M.; NUGENT, J. B. y PASHAMOVA, B. (1998). «Host Country Reforms and FDI Inflows: How Much Difference Do They Make?». World Development, vol. 26, n.음 7, pp. 1299-1314.

[24] GREENHILL, R. y ALI, A. (2013). Paying for progress: how will emerging post-2015 goals be financed in the new aid landscape? Londres: Overseas Development Institute.

[25] HARROD, R. F. (1939). "An Essay in Dynamic Theory». The Economyc Journal, vol. 49, n.- 193, pp. 14-33.London.

[26] HOLLAND, D. y PAIN, N. (1998). The determinants and impact of foreign direct investment in the transition economies: a panel data analysis. National Institute of Economic and Social Research.

[27] HYMER, S. H. (1976). The international Operations of National firms: A study of Foreign Investment. Cambridge: MIT Press.

[28] JOHANSON, J. \& MATTSON, L. (1988): «Internationalization in Industrial Systems a Network Approach». Strategies in Global Competition. Londres: Croom Helm.

[29] KAHAI, S. K. (2011). «Traditional And NonTraditional Determinants Of Foreign Direct Investment In Developing Countries». Journal of Applied Business Research, vol. 20, $\mathrm{n} . .91$.

[30] KATSELI, L. y GLYTSOS, N. (1986). «Theoretical and Empirical Determinants of International Labour Mobility: A GreekGerman Perspective». Centre for Economic Policy Research Working Paper, n.․ 148.

[31] KOCH, D. J., DREHER, A., NUNNENKAMP, P. y THIELE, R. (2008). «Keeping a Low Profile: What Determines the Allocation of Aid by NonGovernmental Organizations?». Kiel Institute Working paper.

[32] KUCERA, D. (2001). «The effects of core workers rights on labour costs and foreign direct investment: Evaluating the conventional wisdom». IILS. Discussion paper, DP. 130. 2001.
[33] LANDRY, A. (1909). «Les trois théories de la population». Revue Scientia, vol. 3, n. 6 . Francia.

[34] LUCAS, R. E. (1988). "On the mechanics of Economic development». Journal of Monetary Economics, vol. 22, n. 1, pp. 3-42.

[35] MARCUELLO SERVOS, C.; CLEMENTE LOPEZ, J. Y FILGUEIRA CHIOSSONI, M. (2010). Dos caras de una misma moneda: Ayuda Oficial para el Desarrollo y Deuda Externa en la cooperación para el desarrollo. Universidad de Zaragoza.

[36] MARTíNEZ CARRERAS, J. U. (1992). Historia del colonialismo y la descolonización. Madrid: Ed. Complutense SA.

[37] MASSEY, D. y ARANGO, J. et al. (1998). Worlds in motion. Understanding international migration at the end of the millenium. Oxford: Clarendon Press.

[38] MOGROVEJO, J. A. (2005). «Factores determinantes de la inversión extranjera directa en algunos países de latinoamérica». Estudios Económicos de Desarrollo Internacional. $A E E A D E$, vol. 5 , n.ㅇ 2 .

[39] NACIONES UNIDAS (2012). Realizing the future we want for all, UN System task team on the Post2015 UN Development Agenda. Disponible en: $h$ ttp://www.un.org (Recuperado: 2014,5 de enero).

[40] NACIONES UNIDAS (2002). Conferencia Internacional de Financiación para el Desarrollo. La Conferencia de Monterrey, 22 de marzo. Disponible en: http://www.un.org/ es/conf/ffd/2002

[41] NACIONES UNIDAS (2005). Declaración de París.

[42] NACIONES UNIDAS (2008). Programa de Acción de Accra.

[43] NONNENBERG, M. y MENDONCA, M. (2004). «The determinants of direct foreign investment in developing countries", January, Working Paper, Institute of Applied Economic Research.

[44] NUNES, C. L.; OSCATEGUI, J. y PESCHIERA, J. (2006). «Determinants of FDI in Latin America", Documento de trabajo 252.

[45] ORGANIZACIÓN MUNDIAL DEL COMERCIO (2014). Informe sobre el Comercio Mundial.

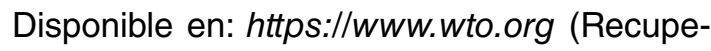
rado: 2014, 5 de enero). 
[46] PÉREZ DÍAZ, J. y MACINNES, J. (2008). «La tercera revolución de la modernidad; la revolución reproductiva». Revista española de investigaciones sociológicas (REIS), vol. 122, n. -1 , pp. 89-118.

[47] POELHEKKE, S. y VAN DER PLOEG, F. (2008). «Growth, Foreign Direct Investment and Urban Concentrations: Unbundling Spatial Lags«. De Nederlandsche Bank NV Working Paper n.․ 195.

[48] PORTER, R. C. (1973). Labor migration and urban unemployment in less developed countries: Comment.

[49] PREBISH, R. (1950). The economic development of Latin America and its Principal Problems. New York: United Nations.

[50] RED EUROSUR (2014). El papel de la Ayuda Oficial al Desarrollo. Disponible en: http:// www. eurosur.org/futuro/fut $78 . \mathrm{htm}$ (Recuperado: 2014, 10 de diciembre).

[51] RIALP, A. y RIALP, J. (2001). «Conceptual frameworks on SMEs' internationalization: Past, present and future trends of research". Reassesing the Internationalization of the Firm, pp. 49-78. Emerald Group Publishing Limited.

[52] RODRIK, D. (2012). La paradoja de la globalización. Antoni Bosh Editor.

[53] ROMER, P. (1986). «Increasing returns and long-run growth». Journal of Policital Economy, vol. 94, n. 5 , pp. 1002-1037.

[54] ROSESTEIN-RODAN (1943). «The problems of industrialization of Eastern and SouthEastern Europe». The Economic Journal, vol. 53, n.. 210/211, pp. 202-211.

[55] SASKIA, C.; VAN DER ZEE, S. C.; HOEK, G.; HARRSSEMA, H. y BRUNEKREEF, B. (1998). «Characterization of particulate air pollution in urban and non-urban areas in the Netherlands». Atmospheric Environment, vol. 32, n. ㅇ 21, pp. 3717-3729.

[56] SEN, A. (2000). El desarrollo como libertad. Madrid: Ed. Planeta.

[57] SHARMA, K., KASHYAP, A., MONTES, M. F. y LADD, P. (2011). Realizing themdevelopment Potential of Diasporas. United Nations University press.
[58] SOLOW (1956). «A contribution to the Theory of Economic Growth». Quarterly Journal of Economics, vol. 70, n.․ 1, pp. 65-94.

[59] STARK, O. (1993). La migración y el trabajo. Madrid: MTAS.

[60] STEIN, P.; GOLAND, T. y SCHIFF, R. (2010). Two trillion and counting: assessing the credit gap for micro, small, and medium-sized enterprises in the developing world. Corporación Financiera Internacional y McKinsey \& Company. Washington D.C.

[61] STEWART, F. y STREETEN, P. (1976). «New strategies for Development: Poverty, Income Distribution, and growth». Oxford Economic papers, vol. $28, \mathrm{n} . \mathrm{\circ} 3$.

[62] STIGLITZ, J. E. (1999). «El papel del Gobierno en el Desarrollo Económico». Cuadernos de Economía, vol. 18, n.ำ 30. Bogotá.

[63] VAN DE KAA, D. J. (2002). «The Idea of a Second Demographic Transition in Industrialized Countries». Paper presented at the Sixth Welfare Policy Seminar of the National Institute of Population and Social Security. Tokyo, Japan, 29 January 2002.

[64] VERNON, R. (1979). «The product life-cycle in a new international environment». Ed. Oxford bulletin of Economics and Statistics, vol. 41, n. - 4, pp. 255-267.

[65] WILLIAMSON, J. (1993). «Democracy and the Washington Consensus». World Development, vol. 21, n.․ 8, pp. 1329-1336. Londres.

[66] WILLIAMSON, O. E. (1974). «The economics of antitrust: Transaction cost considerations». University of Pensilvania Law Review, vol. 122, n.. 6, pp. 1439-1496.

[67] YANGUAS, L. y CAVIEDES, A. (2017). «Impacto de las inversiones privadas en el desarrollo de los países en desarrollo». Boletín Económico de Información Comercial Española, n.․ㅜ 3093.

[68] YANG, D. (2006). «International Migration, Remittances and Household Investment: Evidence from Philippine Migrants' Exchange Rate Shocks». The Economic Journal Royal Economic Society, vol. 118, n. 528 , pp. 591-630. 